\title{
A pessoa idosa e o corpo: uma transformação inevitável
}

\section{The person elderly and the body: an inevitable transformation}

\author{
La persona anciana y el cuerpo: una transformación inevitable
}

Tânia Maria de Oliva Menezes', Regina Lúcia Mendonça Lopes'", Rosana Freitas Azevedo 'II

\begin{abstract}
' Enfermeira, Mestre em Enfermagem. Profa. Adjunta da Escola de Enfermagem da Universidade Federal da Bahia (EEUFBA). Doutoranda no Programa de Pós-Graduação em Enfermagem da EEUFA. E-mail: tomenezes@uol.com.br.

"Enfermeira, Doutora em Enfermagem. Profa. Titular da Área de Saúde da Mulher da EEUfBA. E-mail: reginalm@atarde.com.br.

III Enfermeira, Mestre em Enfermagem. Docente da Faculdade Jorge Amado. Doutoranda no Programa de Pós-Graduação em Enfermagem da EEUFA. E-mail: rosana.azevedo@terra.com.br.
\end{abstract}

\section{RESUMO}

Atualmente, as idades são percebidas como parte do passar do tempo, que é expresso no corpo das pessoas. No imaginário social, o envelhecimento é um processo marcado por desgaste, limitações, perdas físicas e de papéis sociais. As perdas são vistas como problemas de saúde, expressas, em grande parte, na aparência do corpo. Estudo descritivo, exploratório, qualitativo, de iluminação fenomenológica segundo o referencial de Maurice Merleau-Ponty, que teve como objetivo compreender a percepção que o idoso tem do próprio corpo em envelhecimento. Sete idosos, ambos os sexos, idades entre 75 a 83 anos de uma comunidade de Salvador-Bahia participaram da pesquisa. Cinco unidades de significado foram construídas. O corpo que está envelhecendo é percebido pelo idoso como corpo que traz mudanças físicas que, nem sempre, são incorporadas facilmente; apresenta perdas; tem dificuldades de perceber o envelhecimento; se mostra em descompasso com a rapidez da mente; se mostra uma realidade. Tais unidades possibilitaram a construção da unidade de significação "o corpo encarnado é percebido no processo de envelhecimento a partir de signos físicos". Apreendeu-se que integra o processo de ser-no-mundo, vislumbrar o crescimento e o desenvolvimento como movimentos naturais do humano, pois, o envelhecimento é uma possibilidade que se apresenta.

Descritores: Idoso; Imagem corporal; Envelhecimento.

\section{ABSTRACT}

Nowadays, aging is viewed as part of the passage of time, which is experienced in a person's body. In a social setting, aging is seen as a process marked by increased physical limitations, bodily weakening and a reduction of social roles. Such losses are seen as health problems, largely manifest in the body's appearance. A qualitative study, which is descriptive and exploratory and follows the phenomenological methodology according to the referential of Maurice Merleau-Ponty. The study was designed to understand the perception that the elderly has of the own body during aging. A sample of seven elderlies, members of both sexes with ages between 75 and 83 years old was selected from a community in Salvador-Bahia. They participated in the research. Five categories of perceptual interpretation found to represent. The aging body is perceived by the elderly as a body that: ... brings physical changes that are not always easily accommodated; presents losses of function; allows perceptual denial of the development of aging; appears to be slowing while the mind remains alert; appears to reveal one perceived reality. Such categorization reinforces importance of the view that "the aging process in the physical body is perceived through physical signs". Further comprehensive analysis, has suggested that integrating the perceptions of the physical aging process with those of being-in-the world, and allows us to recognize growth and development as a human's natural transformation, in which aging is a possibility that eventually shows up.

Descriptors: Aged; Body image; Aging.

\section{RESUMEN}

Hoy día, las edades son percibidas como parte del pasaje de tiempo, que es expreso en el cuerpo de las personas. En una escena social, el envejecimiento es un proceso marcado por desgastes, limitaciones, pierdas físicas y de reducción de papeles sociales. Se ven las tales pérdidas como problemas de salud, expresas, en gran parte, en la apariencia del cuerpo. Estudio descriptivo, exploratorio, cualitativo que sigue el referencial fenomenológico de Maurice MerleauPonty. El estudio fue diseñado para entender bien la percepción que el anciano tiene del proprio cuerpo durante el envejecer. Una muestra de siete ancianos, de ambos sexos, con las edades entre 75 a 83 años, he sido seleccionada en una comunidad de Salvador-Bahia para participaren de la pesquisa. Cinco categorías de interpretación fueron construidas. El cuerpo que está envejeciendo es percibido por el anciano como un cuerpo que trae cambios físicos que no siempre se acomodan fácilmente; presenta pierdas; tiene dificultades de percibir el envejecer; aparece estar retardando mientras la mente permanece alerta; se muestra una realidad. Esas unidades posibilitaran la construcción de la unidad de significación "el cuerpo encarnado es percibido en el proceso de envejecimiento a partir de signos físicos". He sido aprehendido que integra el proceso de ser-en-el-mundo, vislumbrar el crecimiento e el desarrollo como movimientos naturales un humano, haya visto que el envejecer es una posibilidad a que en el futuro se muestra.

Descriptores: Anciano; Imagen corporal; Envejecimiento. 


\section{NTRODUÇÃO}

$\mathrm{O}$ envelhecimento populacional, que significa um crescimento mais elevado do contingente idoso com relação aos demais grupos etários, não é mais uma preocupação apenas dos países desenvolvidos, onde este fenômeno foi observado já há algum tempo. Hoje, nos países em desenvolvimento, se verificam os maiores índices de mudanças no perfil populacional. No Brasil, diferentemente do que ocorreu nos países mais desenvolvidos, este fenômeno começou mais tarde, e está progredindo muito mais rapidamente, principalmente na população acima de 80 anos, alterando a composição etária dentro do próprio grupo. Esse crescimento da população se deve, em grande parte, ao aumento considerável na expectativa de vida dos brasileiros e que, associado à queda da taxa de natalidade, amplia a proporção relativa de idosos na população ${ }^{(1)}$.

Considerado um grande desafio gerado pelas demandas sociais e econômicas, o envelhecimento populacional vem necessitando a adoção de políticas públicas que sejam capazes de proporcionar um envelhecimento ativo e que respeitem direitos, preferências, capacidades e dignidade dos idosos.

O aumento acentuado do número de idosos trouxe consequências para a sociedade, bem como para os indivíduos que compõem este segmento populacional, fazendo com que o impacto social seja, muitas vezes, mais importante que o biológico, gerando, então, a necessidade de profundas transformações socioeconômicas no país.

O ser humano, diferentemente dos demais seres, foi o único que modificou a própria expectativa de vida, a partir de gradativas mudanças relacionadas às melhorias na qualidade de vida e, em seguida, graças às descobertas técnico-científicas. Com isso, a projeção populacional do Brasil, para o ano 2025, é de 32 milhões de idosos, a maioria com baixo nível socioeconômico e educacional, ao lado de uma alta prevalência de doenças crônicas e incapacitantes, quando o país ocupará, mundialmente, o 60 lugar em relação a pessoas idosas. Em vista das precárias condições sócioeconômicas, estão associadas múltiplas patologias que, não raramente, levam a perda da autonomia, independência e dificuldades de adaptação do idoso ao mundo moderno ${ }^{(1)}$.

Nesta projeção, os dados apontam para um contingente maior da população feminina, trazendo à tona a feminização da velhice, que traz implicações em termos de políticas públicas, pois, uma grande parte das mulheres é viúva, vive só, não tem experiência de trabalho no mercado formal, tem nível de escolaridade geralmente inferior ao dos homens e possui maior esperança de vida, fazendo com que algumas passem pela experiência de declínio biológico, por conta do desenvolvimento de doenças crônicas ${ }^{(1)}$.
As diferenças entre homens e mulheres se aprofundam ao longo do envelhecimento, tomando uma nova dimensão com o prolongamento da vida, pois, se as mulheres vivem mais tempo do que os homens, elas envelhecem em piores condições ${ }^{(2)}$. Na atualidade, as mulheres vivem mais do que os homens devido a fatores biológicos, diferença de exposição aos fatores de risco de morbi-mortalidade e a procura mais acentuada pelos serviços de saúde ${ }^{(3)}$.

Com o crescimento da população, as idades ainda são percebidas como parte do passar do tempo, que é expresso no corpo. No imaginário social, o envelhecimento é um processo marcado por desgaste, limitações e perdas físicas e de papéis sociais. As perdas, muitas vezes, vistas como problemas de saúde e que se manifestam, em grande parte, na aparência do corpo.

Nessa etapa, o ser humano fica mais sujeito às perdas evolutivas em vários domínios, em virtude de sua programação genética, de eventos biológicos, psicológicos e sociais característicos de sua história individual, e daqueles que ocorrem ao longo do curso da história de cada sociedade. No entanto, dizer que na velhice ocorrem mais perdas do que ganho evolutivo não significa dizer que velhice é sinônimo de doença, e nem que as pessoas ficam impedidas de funcionar. Viver significa adaptação ou possibilidade de constante auto-regulação, tanto em termos biológicos, quanto em termos psicológicos e sociais $^{(4)}$.

Todas as modificações que surgem com o envelhecimento podem desencadear no indivíduo a necessidade de transformações, que estarão relacionadas à aceitação ou não deste processo por parte de cada um, e, também, aos valores e interesses assimilados ao longo da vida. Envelhecer bem depende do equilíbrio entre as limitações e as potencialidades do indivíduo, para enfrentar as perdas ocorridas com o envelhecimento ${ }^{(4)}$.

Alguns pesquisadores abordam as modificações anatômicas, fisiológicas e psicossociais ocorridas com o indivíduo e seu processo de envelhecimento ${ }^{(1,5)}$. Sob esses aspectos, o envelhecer constitui-se de vivências singulares que repercutem no cotidiano dos idosos.

Mesmo sabendo que envelhecer e adoecer não sejam são sinônimos, não se pode deixar de lado que algumas doenças são próprias do envelhecimento, e que, com o decorrer do tempo, elas provocam mudanças corporais.

Quando se fala em transformações do corpo, observa-se que os cabelos embranquecem e tornamse mais ralos. Os pêlos embranquecem, embora proliferem em certos lugares. A pele se enruga. As orelhas alongadas estão entre as manifestações mais óbvias da perda de elasticidade do tecido no corpo. A espessura dos sulcos da pele é significativamente 
reduzida no antebraço e dorso das mãos ${ }^{(6)}$.

Cabe destacar que o envelhecimento constitui-se como uma pluralidade de experiências individuais, que impossibilita retê-lo em um conceito ou noção ao investigá-lo, deixando ao alcance do pesquisador somente a possibilidade de confrontar as distintas experiências de envelhecimento umas com as outras, bem como a tentativa de identificar aquelas que são constantes e determinar as razões de suas diferenças $^{(7)}$.

Neste contexto, verifica-se que as transformações do corpo no envelhecimento são visíveis. Com nossa experiência prática no cuidado de enfermagem ao idoso, observamos que algumas mudanças são aceitas; outras, nem sempre, o que leva o idoso a utilizar recursos para que, de alguma maneira, elas se tornem (in)visíveis. Sendo assim, nos sentimos motivadas a pesquisar no idoso de idade avançada como ele vê seu corpo que envelhece.

Nesse sentido, essa pesquisa teve como objeto a percepção do idoso sobre o seu corpo que está envelhecendo e como objetivo compreender a percepção que a pessoa idosa tem do seu corpo em envelhecimento.

\section{MÉTODO}

Esta é uma pesquisa exploratória, descritiva, de natureza qualitativa e de iluminação fenomenológica segundo o referencial de Maurice Merleau-Ponty. É na direção da experiência que a pesquisa fenomenológica e existencial se encaminha, uma vez que tal perspectiva enfatiza a dimensão existencial do viver humano e os significados vivenciados pelo indivíduo no seu estar-no-mundo ${ }^{(8)}$.

O ponto de partida da fenomenologia é de que trazemos conosco o elemento básico de todo conhecimento, ou seja, os pré-reflexivos. Cada ser humano o traz consigo, está no seu cotidiano, sendo necessário examiná-lo para fundamentar o significado e o sentido das coisas. Assim sendo, parte do princípio de que todos nós somos subjetividades que atingimos as objetividades, nas quais a relação entre sujeito e objeto é vista como uma correlação, um está implicado no outro ${ }^{(9)}$.

Esta pesquisa é um recorte do projeto intitulado: Ser Idoso Longevo: desvelando os significados do vivido, aprovado em 07 de dezembro de 2007 pelo Comitê de Ética em Pesquisa da Secretaria de Saúde do Estado da Bahia - SESAB, sob parecer 179/2007, registro 0068.0.053.000-07. O estudo foi realizado com sete idosos de uma comunidade da cidade de Salvador-Bahia, de ambos os sexos, com idades entre 75 a 83 anos, lúcidos e orientados, capazes de manter a entrevista, que aceitaram participar da pesquisa após explicitação do objetivo da mesma e assinatura do Termo de Consentimento Livre e Esclarecido - TCLE, conforme Resolução no 196/96 do Conselho Nacional de Saúde, que dispõe sobre ética em pesquisa com seres humanos. Para manutenção do anonimato dos sujeitos foi atribuído nome fictício de flores.

A técnica de coleta de dados foi a entrevista fenomenológica através da qual podemos apreender a experiência tal como ela é vivenciada pelo narrador $^{(8)}$. Nesse sentido, ao discorrer sobre a entrevista fenomenológica, observamos a necessidade de se estabelecer uma comunhão com o sujeito, ouvir olhando para ele, envolvendo-se com ele, impregnando-se com seus gestos e com toda a sua forma de dizer as coisas, abstraindo-se de qualquer preconceito ou perspectivismo.

A entrevista foi guiada pela seguinte questão norteadora: Como o(a) $\mathrm{Sr}^{(\mathrm{a})}$ vê o seu corpo que está envelhecendo? Após cada entrevista foram transcritos os discursos, com posterior leitura exaustiva dos depoimentos em busca de trechos que permitiram a construção de cinco unidades de significado: o corpo que está envelhecendo é percebido pelo idoso como corpo que: ... traz mudanças físicas que, nem sempre, são incorporadas facilmente; ... apresenta perdas; ... tem dificuldades de perceber o envelhecimento; ... se mostra em descompasso com a rapidez da mente; ... se mostra uma realidade. Essas unidades foram analisadas de acordo com o referencial de autores que trabalham com a temática do envelhecimento e corpo.

$\mathrm{Na}$ etapa seguinte procedemos a construção da unidade de significação: o corpo encarnado é percebido no processo de envelhecimento a partir de signos físicos, ao qual foi utilizado como referencial metodológico a fenomenologia de Maurice Merleau Ponty, que através da sua obra Fenomenologia da Percepção procura elucidar questões como corpo, existência e percepção ${ }^{(10)}$.

\section{RESULTADOS E DI SCUSSÃO}

Os sujeitos da pesquisa foram 7 idosos, sendo 4 mulheres e 3 homens; com idade compreendida entre 75 e 83 anos, estando, em sua maioria, na segunda década da terceira idade. Cinco são casados e duas solteiras. Quanto à escolaridade, apenas Violeta cursou o ensino fundamental I; 3 concluíram o ensino fundamental II e 3 concluíram o ensino médio. Todos os idosos são autônomos e financeiramente independentes.

Após a descrição do fenômeno vivenciado pelos idosos no tocante ao corpo que envelhece, foram destacados os significados, que se constitui a primeira etapa do método. Dentre os vários recortes das falas, trazemos a chamada-chave da unidade de significado O CORPO QUE ESTÁ ENVELHECENDO É PERCEBIDO PELO IDOSO COMO CORPO QUE... para, a seguir, desenvolver cada uma das cinco unidade em separado, com suas respectivas análises. 


\section{... Traz mudanças físicas que, nem sempre, são incorporadas facilmente.}

Em relação às modificações ocorridas no processo do envelhecimento, podemos destacar que as alterações presentes no corpo foram evidenciadas a partir dos depoimentos relatados abaixo:

Apesar de ter poucas rugas, eu sei que eu estou envelhecendo [...] Rosa

[...] eu também noto que as forças que eu tinha naquela época da juventude não tenho mais, mas encarando sempre, não ficando triste, encarando sempre. Que isso é uma conseqüência dos anos, dos janeiros vividos ( J asmim);

[...] eu tenho observado, ao longo do tempo que realmente existe diferença. E essas diferenças, eu fui notando no caminhar (Hortência);

[...] ainda recordo os cabelos normais, hoje já são brancos, totalmente brancos... uma calvície um pouco acentuada, que não existia [...] É... sexualmente já não tenho mais aquela vivacidade que tinha quando era moderno (Lírio);

[...] eu observo pela minha pele, a pele não é mais a mesma. Eu sinto a minha pele flácida (Dália).

A respeito das modificações, cabelos brancos, rugas, flacidez muscular e déficits sensoriais são indicadores inequívocos do processo de envelhecimento. Outras alterações afetam as capacidades funcionais energéticas, como o metabolismo, a circulação e a respiração; e as capacidades funcionais biomecânicas, como diminuição da força, da mobilidade e da resistência(11).

É preciso salientar que as transformações que ocorrem com o corpo que envelhece são inevitáveis, conforme os depoimentos de Rosa, Lírio e Dália, ainda que a pessoa idosa possa, por meio dos recursos disponíveis, tentar retardar as modificações.

Outro aspecto salientado foi no tocante à sexualidade, no qual se observou mudanças com o envelhecimento, apontado no depoimento de Lírio.

É importante perceber na pessoa idosa a forma como essa mudança tem reflexos na sua vida, pois, à sexualidade como força de vida e de bem estar é entendida como a forma de nos colocarmos no mundo enquanto sujeitos e interagirmos com ele $\mathrm{e}^{(11)}$.

Quando analisamos a questão de gênero, as mulheres percebem essas mudanças de forma mais clara, talvez, pelo fato de sua evidência com o envelhecimento. As desvantagens femininas na velhice não se limitam a sua frequente inferioridade econômica, sendo também enorme num campo mais simbólico, que é o da identidade pessoal associada à imagem corporal ${ }^{(2)}$.

As características que definem cotidianamente a pessoa idosa são de alguém com bastante idade e/ou que aparente fisicamente isso, com idéias que remetem, frequentemente, ao passado, inativo, pouco ágil, de quem se espera que tenha uma participação restrita(12). Essa imagem que é veiculada, muitas vezes leva o idoso a não aceitação das modificações, bem como a buscar alternativas que nem sempre trazem resultados que atendam as expectativas.

\section{... Apresenta perdas}

As perdas presentes no envelhecimento são evidenciadas nas falas a seguir:

[...] eu não sou mais a mesma na agilidade. Não posso dizer que pego uma tarefa para levar adiante um dia todo, até o dia todo (Violeta);

Eu diria que a questão da movimentação[...] os movimentos já são menores do que era inicialmente. A mente já não tem mais aquela acuidade. Esqueço, às vezes, com facilidade [...] (Lírio);

Também eu sinto certo cansaço, principalmente quando eu faço, exerço uma tarefa mais difícil, com mais tempo de duração, o que não acontecia no passado (Dália)

O imaginário social retrata o processo de envelhecimento marcado por desgaste, limitações, perdas físicas e de papéis sociais, que de alguma forma foram evidenciados nos depoimentos de Violeta, Lírio e Dália.

A esse respeito, encontramos que as perdas são tratadas, principalmente, como problemas de saúde, expressas em grande parte na aparência do corpo, pelo sentimento em relação a ele e ao que lhe acontece: enrugamento, encolhimento, descoramento dos cabelos, reflexos mais lentos, menos agilidade ${ }^{(13)}$

O processo de envelhecimento provoca inúmeras alterações no organismo humano, o que pode levar o indivíduo a sofrer mudanças no seu cotidiano(14).

Como gerontólogos, não se pode permitir que a pessoa idosa perceba o processo de envelhecimento apenas como perdas, pois que os ganhos também existem e precisam ser evidenciados, para que se ultrapasse todos os limites e se permita que sua existência seja vivida com qualidade e dignidade.

\section{... Tem dificuldades de perceber o envelhecimento}

Os depoimentos que se seguem refletem a dificuldade que os idosos apresentam de perceber que estão envelhecendo:

[...] a gente reflexiona que quem tá entrando agora na idade da velhice somos nós, da minha faixa de idade (Lírio);

[...] eu não fico pensando somente nisto... que eu estou envelhecendo. Esqueço um pouco esse aspecto do envelhecimento, [...] que eu ainda posso conseguir, que eu vou chegar lá e esquecer essa história de envelhecer (Dália)

A fala de Dália expressa o distanciamento de pensar o envelhecimento. Nos dias atuais, a idade continua sendo expressa através do corpo No 
cotidiano, as idades ainda são percebidas, principalmente, como parte do passar do tempo, mimetizando como duração e ritmo os ciclos da natureza e as estações, o que é expresso no corpo das pessoas ${ }^{(12)}$.

Ainda sobre a dificuldade na percepção, encontramos que a velhice é particularmente difícil de assumir. No imaginário social, o envelhecimento é um processo que concerne à marcação da idade como algo que se desenrola como desgaste, limitações crescentes e perdas, físicas e de papéis sociais $^{(13)}$

\section{... Se mostra em descompasso com a rapidez da mente}

Alguns depoimentos expressam essa relação corpo-mente, como apresentada a seguir:

[...] interessante é que a gente só percebe que está envelhecendo quando vai fazer uma ação qualquer, que a mente sabe que sempre fez, mas agora o corpo não responde. Então, aí a gente começa a perceber as nuances do envelhecimento (Cravo);

Eu percebo as limitações da mente... Eu já não consigo fixar determinados textos com tamanha presteza de detalhes [...] (Jasmim)

Em nossa prática profissional, a falta de sincronia entre corpo e mente é evidente, o que, muitas vezes, faz com que o idoso perceba, de forma mais clara, que está envelhecendo. Mesmo assim, o estímulo para a execução das atividades deve sempre existir, como forma de preservar a sua independência. As limitações que surgem devem ser trabalhadas de maneira tranquila, a fim de que a pessoa idosa não se sinta desestimulada no desempenho de suas funções.

Os cuidados que podemos dispensar ao corpo são muitos, com o intuito de construir nossa imagem corporal, porém, não podemos descuidar da nossa mente, pois envelhecer satisfatoriamente depende do equilíbrio entre as limitações e as peculiaridades do indivíduo, para que possamos lidar com as perdas inevitáveis.

\section{... Se mostra uma realidade}

Algumas falas retratam a realidade do corpo que envelhece, como as que se destacam:

Apesar de ter poucas rugas, eu sei que eu estou envelhecendo[...] mas, os próprios médicos, quando vêem minha idade ficam surpresos [...] (Rosa);

[...] essas coisas que não dá mais para fazer [...] Isso faz parte da vida, o tempo vai passando e a gente vai ter que se conformando com as coisas (Violeta).

A realidade do corpo, evidenciada nas falas, podem traduzir diferentes sentidos na vida da pessoa idosa, pois, muitas vezes, esta compreensão da realidade pode determinar a forma como se dá a relação social.
Nesse sentido, é importante considerar as maneiras pelas quais a forma do corpo (suas características formais, tipo volume, vigor, beleza) é culturalmente codificada para operar como um indicador de poder social e prestígio(15). Essas dimensões da vida social são de extrema valia, quando considerado o processo de envelhecimento.

Através do corpo podemos estar em contato com o mundo, mas é necessário que esse corpo esteja sadio, funcionando adequadamente, para termos acesso ao mundo e aos objetos, enquanto sujeitos encarnados que somos ${ }^{(16)}$.

Há no depoimento de Rosa uma marca inexorável do envelhecimento: a presença das rugas. Essa é apenas uma marca, entre tantas outras que figuram na auto-imagem, e que pode ser capaz de desencadear uma negação da velhice. Como profissionais da área da gerontologia é imprescindível sabermos conduzir os idosos diante destas questões, a fim de que o processo de envelhecimento transcorra com aceitação, e que eles possam lidar com as transformações que surgem.

Entre as muitas formas de expressão da idade, o corpo se apresenta como uma delas. A esse respeito percebe-se que no cotidiano, entretanto, as idades ainda são vistas principalmente como parte do passar do tempo, mimetizando como duração e ritmo os ciclos da natureza e as estações, o que é expresso no corpo das pessoas ${ }^{(13)}$.

Tais unidades acima descritas possibilitaram a construção da unidade de significação abaixo, que foi analisada à luz da fenomenologia de Maurice Merleau-Ponty, a partir de seu pensamento expresso em Fenomenologia da Percepção.

\section{O CORPO ENCARNADO É PERCEBIDO NO PROCESSO DE ENVELHECIMENTO A PARTIR DE SI GNOS FÍ SI COS}

No segundo momento da análise surge a compreensão do Ser, que é o fio condutor da compreensão interpretativa, que é sustentada no referencial metodológico e desvela o Ser ou fenômeno. Este momento é fundamentado, principalmente, pelo pensamento de Merlau-Ponty.

“O corpo é o veículo de ser no mundo, e ter um corpo é para um ser vivo, juntar-se a um meio definido [...] e neste sentido tenho consciência do meu mundo por meio do meu corpo"(10).

São inúmeras as dificuldades enfrentadas decorrentes de alterações na integralidade corporal, demonstrando que o corpo possui um forte significado da vivência. Sob esse aspecto, encontrase que o corpo é obra de arte, é a sede na qual se articulam todos os significados, é o lugar de encontro das nossas experiências ${ }^{(10)}$.

A velhice se apresenta, de alguma maneira, através da imagem do corpo e por mais que o indivíduo encontre uma imagem mais ou menos 
convincente, mais ou menos satisfatória de si mesmo, não pode fugir das modificações que o corpo vai apresentando com o passar dos anos.

Há um despreparo do ser humano em aceitar qualquer alteração em seu corpo, pois, como Merleau-Ponty assevera, nós o comparamos a uma obra de arte: "Mas eu não estou diante de meu corpo, estou em meu corpo, ou antes, sou meu corpo. [...] o nosso corpo é comparável à obra de arte. Ele é um nó de significações vivas e não a lei de um certo número de termos co-variantes"(10).

Em concordância com este pensamento, afirmase que através do nosso corpo nós somos seres do mundo, e por intermédio do corpo, a consciência é conduzida para as coisas ${ }^{(10)}$, como o filósofo assim afirma: "nós percebemos o mundo com o nosso corpo"(17).

A filosofia da percepção na compreensão merleaupontiana aponta diante de nós a tarefa de compreender o corpo como fundamento na construção de saberes e na produção de subjetividades. $\mathrm{Na}$ concepção fenomenológica da percepção, a apreensão do sentido se dá através do corpo, quando se trata de uma expressão criadora a partir dos diferenciados olhares sobre o mundo ${ }^{(18)}$

Numa sociedade que privilegia a juventude e circunscreve-se à beleza jovem, o corpo velho remete à antevisão da senilidade, perdas e proximidade da morte ${ }^{(12)}$. Ainda a esse respeito, encontramos que em face da obsessão pela juventude e pela aparência na cultura ocidental, e dada à fragilidade do corpo na velhice, a cultura de massa, que é também uma cultura do consumo, normalmente opõe as duas idades extremas, a juventude e a velhice, sendo esta última apresentada como um problema da medicina. Com o pretexto de curar a velhice, a cultura de massa produz tanto a invisibilidade quanto a hipervisibilidade do corpo das velhas mulheres: a dicotomia entre a beleza e destruições do tempo evoca, por analogia, a dicotomia entre a saúde e a doença associadas à velhice, cotidianamente reafirmadas pela mídia e pela publicidade $^{(2)}$.

Essa massificação da mídia pela eterna juventude faz com que o idoso, muitas vezes, viva em eterno conflito pelo que se apresenta em seu corpo e por não alcançar o que se espera, pelas contingências inerentes ao processo de envelhecimento.

O corpo do velho é o corpo 'diferente', comparado - em desvantagem - com o modelo de corpo e beleza jovem vigente na sociedade, manipulável para se aproximar deste ${ }^{(12)}$. Assim, é preciso que a pessoa idosa não procure na imagem do corpo os padrões de beleza da mídia, pois, sabese que a sociedade, desempenha papel de destaque na maneira como conduz os seus membros para a importância que atribuem a seus corpos.
É preciso reconhecer que o ciclo de vida consiste numa série de etapas relacionadas entre si e num todo integrado ${ }^{(19)}$. No corpo encontram-se embutidas as questões referentes ao bem estar, à saúde, a dor, a doença e ao processo do envelhecimento. Através da relação "eu-corpo-outro-mundo", o ser humano vive sua corporeidade de modo significativo para si próprio, e deseja ser reconhecido, neste valor significativo pelos outros ${ }^{(16)}$.

Não se pode deixar de considerar os diferenciais de gênero quando se trata de corpo. Em primeiro lugar, fica evidente que as mulheres procuram mais a cosmética e os cuidados com o corpo do que os homens, face às inúmeras modificações que acontecem e que, culturalmente, são determinantes do acentuado consumismo em nosso meio.

Além disso, as mulheres sempre foram tradicionalmente avaliadas pela aparência física e pela capacidade reprodutiva. Em suma, pelo estado de seu corpo, pela beleza que possa exercer, atração, pela saúde que permita reproduzir, pela docilidade de um corpo que se deixe moldar ${ }^{(13)}$.

A experiência vivida é habitada por esse sentido estético presente na corporeidade, compreendida como campo de possibilidades para nos aprofundarmos nos acontecimentos, retomando sentidos e significados da linguagem e do conhecimento $^{(18)}$.

É preciso, pois, desmistificar essa visão de corpo no envelhecimento, para que se possa viver este processo de forma ativa, com qualidade de vida, independente de todas as modificações que estejam inscritas no corpo.

Por outro lado, se deve considerar o idoso como uma parte crescente da população, ativo e atuante na sociedade, mas que apresenta sua particularidades impostas pela idade ${ }^{(19)}$.

\section{CONCLUSÃO}

A pesquisa permitiu compreender a percepção da pessoa idosa sobre o seu corpo que envelhece, e ficou evidente nas diversas unidades de significado apresentadas, que o corpo que está envelhecendo é percebido de diversas maneiras.

Com esta pesquisa foi possível compreender que o envelhecimento não ocorre de maneira homogênea, pois há sempre partes, órgãos ou funções do corpo que se mantêm muito mais jovens, conservados e sadios do que outros.

As mulheres se preocupam mais com o seu corpo, a sua aparência, pela beleza que possa exercer. Nestas depoentes idosas, verifica-se uma série de alterações que são próprias do envelhecimento, mas que vão se constituindo em marcas corporais que podem modificar o comportamento e estilo de vida dessas mulheres, principalmente no que se refere ao corpo. O desgaste em maior abundância do corpo feminino pode estar 
relacionado ao fato de que, o corpo da mulher passa pela experiência da gravidez, parto e amamentação.

Há, por parte da pessoa idosa, a nítida percepção de seu corpo que envelhece e apresenta uma série de limitações, bem como a reação social a estas transformações.

A pesquisa também evidenciou a dificuldade de aceitação do corpo que envelhece. Ao abordar o envelhecimento, apesar desta busca constante pelo corpo esbelto e sem limites, da mídia com freqüência nos apresentar o modelo de corpo que se deve ter, não podemos esquecer que este é um processo progressivo e irreversível, aos quais modificações fisiológicas, bioquímicas e psicológicas são conseqüentes à ação do tempo, e essas mudanças não vão favorecer a manutenção desse corpo ideal.

É preciso, pois, trabalhar no decorrer do processo de crescimento e desenvolvimento, para aceitação das inevitáveis transformações, de forma a permitir um envelhecimento ativo e com qualidade de vida. A enfermagem desempenha importante papel frente às peculiaridades da pessoa idosa, na medida em que da ênfase ao potencial que ela é capaz de utilizar diante das modificações que são inerentes ao processo de envelhecimento, possibilitando, dessa maneira, o envelhecer saudável, mesmo com as inevitáveis modificações do corpo.

\section{REFERÊNCI AS}

1. Ramos LR. Epidemiologia do envelhecimento. In: Freitas EV, Py L, Néri AL, Cançado FAX, Gorzoni ML, Rocha SM, editors. Tratado de geriatria e gerontologia. Rio de Janeiro: Guanabara Koogan; 2006. p. 72-8.

2. Attias-Donfut C. Sexo e envelhecimento. In: Peixoto, CE. Família e envelhecimento. Rio de Janeiro: FGV; 2006. p. 85-108.

3. Schoueri J unior R, Ramos LR, Papaléo Netto $M$. Crescimento populacional: aspectos demográficos e sociais. In: Papaléo Neto $M$; Carvalho Filho ET, organizador. Geriatria: fundamentos, clínica e terapêutica. São Paulo: Atheneu; 2005. p. 9-29.

4. Neri AL, Cachioni M. Velhice bem-sucedida e educação. In: Neri AL, Debert GG. Velhice e sociedade. São Paulo: Papirus; 1999. p. 113-40.

5. Guimarães RM, Camargos EF. A avaliação do velho doente. In: Guimarães RM, Cunha UGV. Sinais e sintomas em geriatria. São Paulo: Atheneu; 2004. p. 7-16.

6. Eliopoulos C. Enfermagem gerontológica. In: Eliopoulos C. Modificações comuns do envelhecimento. Porto Alegre: Artmed; 2005. p. 7494.

7. Siqueira RL, Botelho MIV, Coelho FMG. A velhice: algumas considerações teóricas. Ciênc. saúde coletiva. 2002; 7(4): 899-906.

8. Dutra E. A narrativa como uma técnica de pesquisa fenomenológica. Estud. Psicol. (Natal).
2002; 7(2):371-8.

9. Josgrilberg RS. A fenomenologia como novo paradigma de uma ciência do existir. In: Pokladek, DD. A fenomenologia do cuidar: prática dos horizontes vividos na área da saúde, educacional e organizacional. São Paulo: Vetor; 2004. p. 31-49.

10. Merleau-Ponty M. Fenomenologia da percepção. São Paulo: Martins Fontes; 1999. 662 p.

11. Neri AL. O fruto dá sementes: processos de amadurecimento e envelhecimento. In: Neri AL, organizador. Maturidade e velhice: trajetórias individuais e socioculturais. Campinas: Papirus; 2001. p. 11-52.

12. Mota AB. Visão antropológica do envelhecimento. In: Freitas EV, Py L, Néri AL, Cançado FAX, Gorzoni ML, Rocha SM. Tratado de geriatria e gerontologia. Rio de Janeiro: Guanabara Koogan; 2006. p. 78-82 13. Mota AB. Envelhecimento e sentimento do corpo. In: Minayo MCS, Coimbra Júnior CEA. Antropologia, saúde e envelhecimento. Rio de Janeiro: Fiocruz; 2002. p. 37-50.

14. Machado TR, Oliveira CJ, Costa FBC, Araujo TL. Avaliação da presença de risco de quedas em idosos. Rev. Eletr. Enf. [Internet]. 2009 [cited 2009 jul 30]; 11(1):32-8. Available from: http://www.fen. ufg. br/revista/v11/n1/v11n1a04.htm 15. Featherstone M. O curso da vida: corpo, cultura e o imaginário no processo de envelhecimento. In: Debert GG, organizador. Antropologia e velhice. Coleção Textos Didáticos 13. Campinas: Instituto de Filosofia e Ciências Humanas/Universidade Estadual de Campinas; 1994. p. 49-71.

16. Silva MR, Lopes RLM. The american tegumentary leishmaniasis in the perspective of who lives it. Online braz j nurs [Internet]. 2004 [cited 2009 agu 13]; 3(2). Available from: http://www.uff.br/nepae/siteantigo/objn302silvalopes.htm.

17. Capalbo, C. Corpo e existência na filosofia de Maurice Merleau-Ponty. In: Castro DSP, Piccini JD, J osgrilberg TAG, Goto TA. Corpo e existência. São Paulo: UMESP; 2003. p. 11-23.

18. Nobréga TP. Corpo, percepção e conhecimento em Merleau-Ponty. Estud. psicol. (Natal) [Internet]. 2008 [cited 2009 agu 13];13(2):141-8. Available from: http://www.scielo.br/pdf/epsic/v13n2/06.pdf. 19. Martins JJ, Barra DCC, Santos TM, Hinkel V, Nascimento ERP, Albuquerque GL, et al. Educação em saúde como suporte para a qualidade de vida de grupos da terceira idade. Rev. Eletr. Enf. [Internet]. 2007 [cited 2008 jan 20];9(2):443-56. Available from: http://www.fen.ufg. br/revista/v9/n2/v9n2a12.htm.

Artigo recebido em 14.08.08

Aprovado para publicação em 28.05.09.

Artigo publicado em 30.09.09. 